\title{
Anomalous Origin of a Coronary Artery
}

\author{
Ibrahim Tanidir • Alper Güzeltaş • Ender Odemis
}

Published online: 6 May 2010

(C) Springer Science+Business Media, LLC 2010

To the Editor,

We read with interest the case report by Liu et al. regarding an extremely rare occurrence in the medical literature, the anomalous origin of a coronary artery from the right brachiocephalic trunk [1]. Two previous cases were cited in their report. During our research on truncus arteriosus with a single ventricle, we encountered an additional case to those already reported by Liu et al. In 1956 Cree reported a single coronary artery that arose from the innominate artery and divided into a right coronary artery, running down the atrioventricular groove to supply branches to the right atrium and anterior surface of the ventricle, and a left marginal artery, running down the left margin of the ventricle to the apex and supplying branches to the posterior surface of the ventricle, in a patient with single ventricle and truncus arteriosus [2]. With this case, there are now four case reports of this type of coronary artery origin abnormality in the medical literature.

\section{References}

1. Liu F, Huang G, Zhang J (2010) Anomalous origin of a coronary artery from the right brachiocephalic trunk associated with complex congenital heart disease. Pediatr Cardiol 1:163-165

2. Cree IC (1956) Truncus arteriosus and a single ventricle. Br Heart J 4:553-556
I. Tanidir $(\bowtie) \cdot$ A. Güzeltaş · E. Odemis Department of Pediatric Cardiology, Istanbul Mehmet Akif Ersoy Thoracic and Cardiovascular Surgery Training and Research Hospital, Küçükçekmece, 34303 Istanbul, Turkey e-mail: cansaran@yahoo.com 